\title{
Smoking Habits of Children Institutionalized in Family Care Homes in Mures and Harghita County
}

\author{
Ferencz Lorand ${ }^{1 *}$, Finta Hajnal ${ }^{1}$, Schmidt Lorand ${ }^{2}$, Balint losif ${ }^{1}$, Nadasan Valentin ${ }^{1}$, Abram Zoltan ${ }^{1}$ \\ ${ }^{1}$ Department of Hygiene, University of Medicine and Farmacy, Targu Mures, Romania \\ 2 DGASPC Tîrgu Mures, Romania
}

\begin{abstract}
Background: Smoking is a problem of the modern world and annually produces more victims, and due to ignorance and lack of health education in our country the disease diagnosis is made at an advanced stage. Many studies show that, young people aged between 10 and 18 are smokers and start smoking at an increasingly early age. Objective: The purpose of this study was to assess the smoking habits of institutionalized children in family care homes from Harghita and Mures county. Methods: The method chosen was a sociological survey based on questionnaires. Our study included 254 children institutionalized in family care homes in Mures county and 254 children from Harghita county. Statistical analysis was performed using the Statistical Package for Social Sciences. Results: A statistically significant difference was obtained analyzing the number of smokers from the group of children under 12 years in Mures compared to the Harghita county. More than half of children smoked their first cigarette after they entered in family care homes in both counties and the most common setting in which the children were smoking was when being together with their friends. Conclusions: In Mures county the number of smokers under the age of 12 was significantly higher than in Harghita county. Despite the educational classes and institutional regulations of smoking, more than half of children smoke. The decisive role in testing of smoking are the friends. Due to the very high number of underage smokers, the prevention and education hours have an unquestionable importance.
\end{abstract}

Keywords: smoking, children, institutionalized

Received: 9 December 2014 / Accepted: 4 June 2015

\section{Introduction}

Smoking is a problem of the modern world and annually produces more victims, and due to ignorance and lack of health education in our country the disease diagnosis is made at an advanced stage. Globally, tobacco consumption kills nearly six million people a year through both direct use and the deadly effects of second-hand smoke - more than $70 \%$ of whom reside in low- and middle-income countries [1]. Tobacco use is a global epidemic among young people. Most young smokers become adult smokers. Despite thousands of programs to reduce youth smoking and hundreds of thousands of media stories on the dangers of tobacco use, generation after generation continues to use these deadly products, and family after family continues to suffer the devastating consequences. Prevention efforts must focus on both adolescents and young adults because among adults who become daily smokers, nearly all first use of cigarettes occurs by 18 years of age (88\%), with $99 \%$ of first use by 26 years of age [2].

Increasing interest in demand for, and use of proven tobacco-cessation products and services represents an extraordinary opportunity to reduce adult tobacco use - the nation's single greatest cause of preventable death disease, and a major source of healthcare burdens and disparities [3].

Early subjective experience (ESE) with smoking may be a potential predictor of further progression from experimentation to more regular smoking among adolescents.

* Correspondence to: Lorand Ferencz

E-mail: lorandferencz@yahoo.com
Self-reports of ESE demonstrate good short-term temporal stability. The early unpleasant smoking experience might have a different role in different stages of smoking acquisition [4]. Results from The Global Adult Tobacco Survey (GATS) in Romania show that the highest proportion of initiation of daily smoking took place at age 17$19(43.1 \%)$, followed by ages 15 to $16(21.7 \%)$ and then 20 or over $(18.1 \%)$. The lowest proportion was found for less than age $15(17.1 \%)$ [5].

The purpose of this study was to assess the smoking habits of institutionalized children in family care homes from Harghita and Mures county.

\section{Material and Methods}

The method chosen was a sociological survey based on questionnaires. Our study included 254 children institutionalized in family care homes from Mures county and 254 children from Harghita county. At the beginning of 2014 the institutionalized children voluntarily completed an anonymous questionnaire with 57 questions under supervision.

During the research were always respected the principles of anonymity and confidentiality. The questions were related to the smoking behavior of young people and smoking habits of their environment . Questions addressed topics related to tobacco advertising and publicity on anti-smoking campaigns, educational discussions related to smoking, plans for withdrawal. The collaboration protocols were signed between UMF Targu Mures and DGASPC Harghita and Mures . 
Statistical analysis was performed using the Statistical Package for Social Sciences (SPSS, version 21). Data were labelled as nominal or quantitative variables. Nominal variables were characterized by means of frequencies. Quantitative variables were tested for normality of distribution using Kolmogorov-Smirnov test and were described by mean \pm standard deviation or median and percentiles (25; $75 \%$ ), whenever appropriate. The frequencies of nominal variables were compared with a chi-square test. Differences in the mean or median between groups were analysed using the $t$ test. The level of statistical significance was set at $\mathrm{p}<0.05$.

\section{Results}

The average age of children in the study group was 14.95 years in Mures (MS) county and 15.14 years in Harghita (HR) county. In the study group were 136(53.5\%) boys, 117 (46.1\%) girls in MS and 123 (48.4\%) boys, 130 $(51.2 \%)$ girls in HR. The interviewed children that are in system under 1 year represent $9.1 \%$ from HR and $14.6 \%$ from MS. From the group protected in family homes between $1-3$ years $31.5 \%$ were in HR and $22.4 \%$ in MS. In the group of children who have 3-6 years in this system $33.5 \%$ were in HR, $21.7 \%$ in MS and $6-10$ years $22.4 \%$ in HR, respectively $28 \%$ in MS. The number of children protected in family homes over 10 years $(12.2 \%)$ is significantly higher in MS compared to HR county (1.2\%) (Fig. 1).

A number of 155 children (61\%) in HR , 138 children (54.3\%) in MS county had tried cigarette smoking, even one or two puffs. From the totally group of boys and girls examined in HR, 83 boys (67.5\%) and 71 girls (54.6\%) have tried smoking. Of the totally group of children (boys and girls) examined in MS 74 (54.4\%) boys and $64(54.7 \%)$ girls have tried smoking.

$16.1 \%$ of children surveyed in HR and $16.9 \%$ of MS never received information about smoking. $41.7 \%$ from MS county group received information about smoking

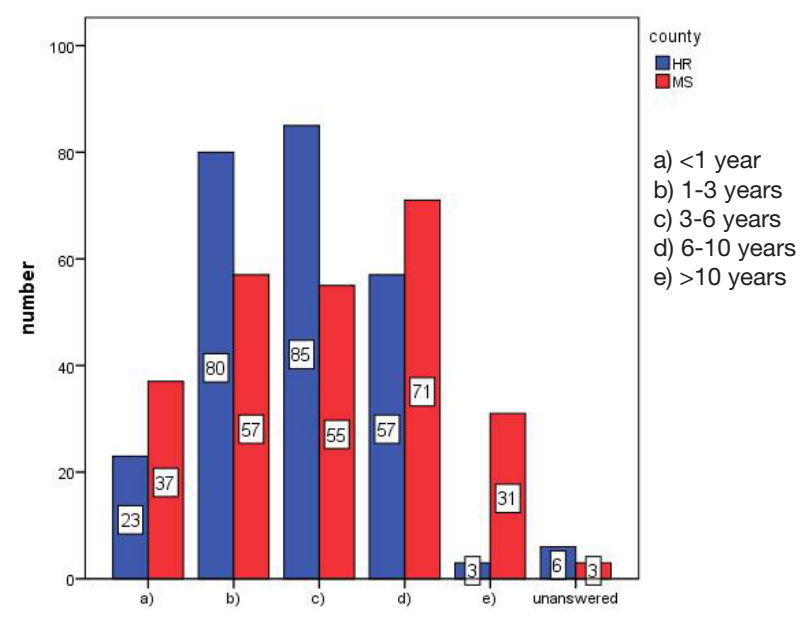

Fig.1. Number of years in family care an hour. $39.8 \%$ of HR received information about smoking over 3 hours (Fig.2).

In HR county 41 (33.3\%) of boys, 21 (16.1\%) of the girls smoked their first cigarette before age 12. In MS county $38(27.9 \%)$ of boys, $25(21.4 \%)$ of the girls smoked their first cigarette before age 12 . the age group below 10 years the number of girls who smoke was $13.7 \%$ in MS and $4.6 \%$ in HR. From all the children surveyed, 64 (25.2\%) from HR and 84 (33.1\%) from MS started smoking after they arrived in family homes (Fig.3).

The most common environment in which the children were smoking was when they were together with their friends, $50.00 \%$ cases in HR and $44.5 \%$ cases in MS. Children who smokes alone were only 17 (6.7\%) in HR, $18(7.1 \%)$ in $M S$, and a very small percentage in both counties smokes together with adults (Fig.4).

\section{Discussion}

Average age of the children surveyed in the two counties is almost similar. No significant differences between ages in the counties.

We found significant differences between the two counties regarding the period of protection in family homes. The number of children protected in family homes over 10 years is significantly higher in MS compared to HR county ( $\mathrm{p}=0.0001)$.

More than half of children had tried cigarette smoking, even one or two puffs in both counties. Tobacco use is started and established primarily during adolescence [6,7]. A similar finding was shown by a study results from NSDUH, among youths aged 12 to 17 who smoked cigarettes in 53.9 percent [8].

The percentage of boys smokers in HR is higher than girls, but we did not found a statistical significant difference ( $p=0.12)$. In MS the percentage of girls / boys is almost similar $(\mathrm{p}=0.84)$. Some studies was shown the tobacco uptake in pre-adolescence differs between genders,

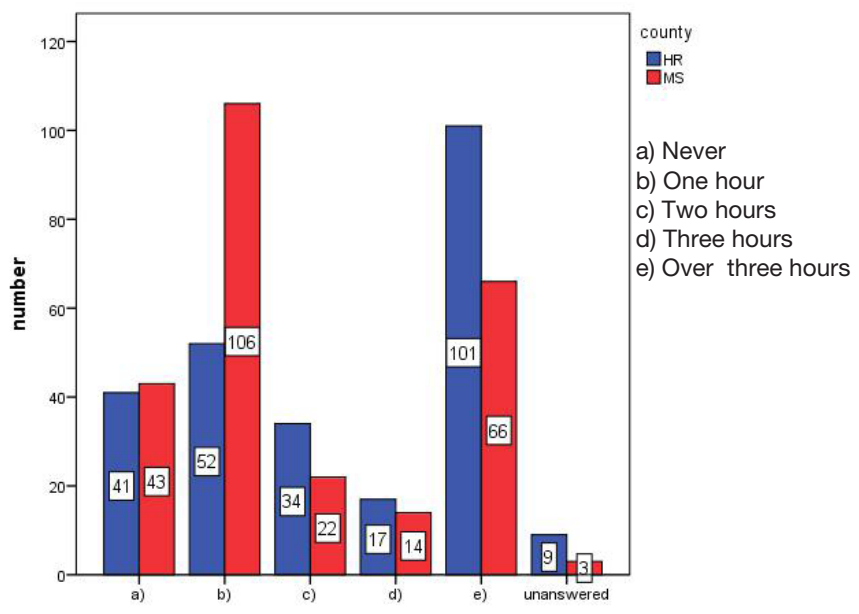

Fig. 2. Information about smoking 


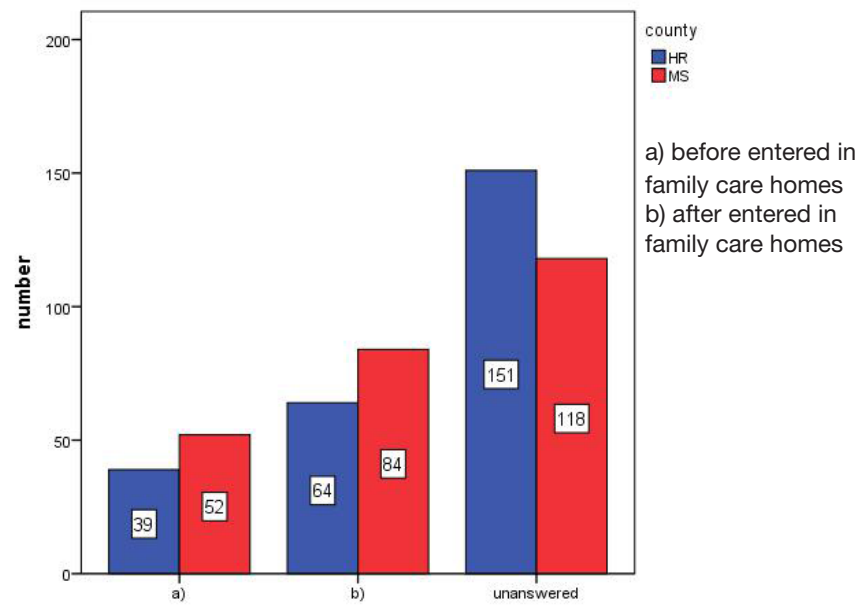

Fig. 3. Starting smoking

with an earlier initiation among boys and a more rapid transition to regular smoking among girls [9].

A similar proportion in the two counties received no information about smoking. Only a quarter of respondents in Mures has received more than three hours of teaching. One of the approach is an information deficit of programs that provides information about the health risks and negative consequences of tobacco [10].

In HR county a significantly higher number of boys $(\mathrm{p}=0.01)$ versus girls smoked their first cigarette before age 12. In the age group below 10 years the number of girls smokers in MS was significantly higher than the number of girls smokers in HR ( $\mathrm{p}=0.01)$.

Though very little data about smoking is regularly collected for kids under 12, the peak years for first trying to smoke appear to be in the sixth and seventh grades (or between the ages of 11 and 13), with a considerable number starting even earlier [11].

More than half of children smoked their first cigarette after they entered in family care homes in both counties.

The most common environment in which the children were smoking was when they were together with their friends, and in a very small percentage when they were together with adults. There were no significant differences between the two counties. A number of longitudinal studies have explored the role of friends, parents smoking in children's smoking acquisition [12], and these results suggest that close friend, parents smoking were similarly important influences on children's smoking. Results showed that perceived friends smoking approval and behavior were associated positively with adolescents smoking, as was the community-level prevalence of adult daily smoking [13].

\section{Conclusions}

Despite the educational classes and institutional regulations of smoking, more than half of children smoke. The decisive role in testing of smoking are the friends.

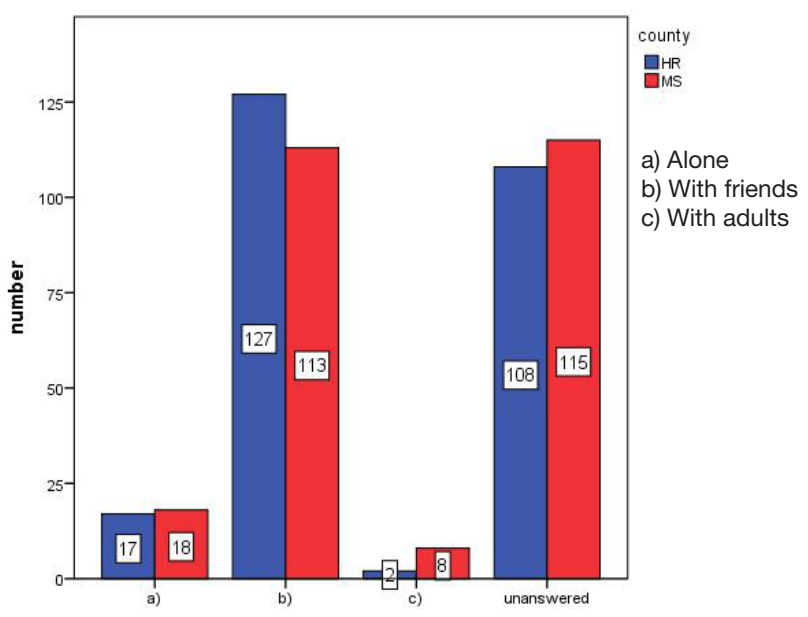

Fig. 4. Smoking habits

Due to the very high number of underage smokers, the prevention and education hours have an unquestionable importance.

Given the influence of friends, anti-tobacco education should be applied to all children of the same age. It is very important to organize events about smoking and its harmful consequences.

Internal rules of the houses regarding the regulations of smoking in- and around the house need checked and updated.

\section{Acknowledgements}

Information reported in this presentation was supported by the Fogarty International Center of the National, Institutes of Health under Award Number R01TW009280.

This paper was published under the frame of European Social Found, Human Resources Development Operational Programme 2007-2013, project no. POSDRU/159/1.5/S/136893

\section{References}

1. World Health Organization. WHO Framework Convention on Tobacco Control. Geneva, Switzerland: World Health Organization; Statement of the World Health Organization in Relation to the issue of Standardized Tobacco Product Packaging WTO Trips Council Meeting; Geneva 28-29 October 2014. http://www.who.int/fctc/mediacentre/news/2014.

2. Preventing tobacco use among youth and young adults : a report of the Surgeon General. - Atlanta, GA.: Dept. of Health and Human Services, Centers for Disease Control and Prevention, National Center for Chronic Disease Prevention and Health Promotion, Office on Smoking and Health; Washington, D.C., 2012, Pag.3-8.

3. Cathy L. Backinger, Amber Thornton-Bullock, Cindy Miner, et al. "Building Consumer Demand for Tobacco-Cessation Products and Services The National Tobacco Cessation Collaborative's Consumer Demand Roundtable" Am J Prev Med 2010;38(3S)S307-S311.

4. Róbert Urbán, Erin Sutfin. Do Early Smoking Experiences Count in Development of Smoking?: Temporal Stability and Predictive Validity of an Early Smoking Experience Questionnaire in Adolescents." Nicotine Tob Res, 2010;12:1265-1269.

5. World Health Organization. WHO Framework Convention on Tobacco Control. Geneva, Switzerland: World Health Organization, Tobacco Free Initiative (TFI), Surveillance and monitoring, Global Adult Tobacco Survey (GATS), Romania, 2011, http://www.who.int/tobacco/surveillance/ survey/gats/gats_romania_report_2011.pdf. 
6. U.S. Department of Health and Human Services. Preventing Tobacco Use Among Young People: A Report of the Surgeon General. Atlanta: U.S. Department of Health and Human Services, Centers for Disease Control and Prevention, Office on Smoking and Health, 1994.

7. U.S. Department of Health and Human Services. Preventing Tobacco Use Among Youth and Young Adults: A Report of the Surgeon General. Atlanta: U.S. Department of Health and Human Services, Centers for Disease Control and Prevention, National Center for Chronic Disease Prevention and Health Promotion, Office on Smoking and Health, 2012.

8. Substance Abuse and Mental Health Services Administration, Results from the 2013 National Survey on Drug Use and Health: Summary of National Findings, NSDUH Series H-48, HHS Publication No. (SMA) 14-4863. Rockville, MD: Substance Abuse and Mental Health Services Administration, 2014.

9. Galanti MR, Rosendahl I, Post A, Gilljam H: Early gender differences in adolescent tobacco use-the experience of a Swedish cohort, Scand J Public Health, 2001;29:314-317.
10. European Smoking Cessation Guidelines: The authoritative guide to a comprehensive understanding of the implications and implementation of treatments and strategies to treat tobacco dependence. Revised 1st edition. October 2012. 23-40.

11. Johnston, LD, et al., Monitoring the Future national survey results on drug use, 1975-2012. Volume I, Secondary school students, 2013, http://www.monitoringthefuture.org/pubs/monographs/mtf-vol1_2012. pdf.

12. Bricker JB, Peterson AV, Robyn Andersen M, Leroux BG, Bharat Rajan K, Sarason IG.: Close friends', parents', and older siblings' smoking: reevaluating their influence on children's smoking., Nicotine Tob Res, 2006;8:217-226.

13. Thrul J, Lipperman-Kreda S, Grube JW, Friend KB: Community-level adult daily smoking prevalence moderates the association between adolescents' cigarette smoking and perceived smoking by friends., J Youth Adolesc, 2014;43:1527-1535 